\title{
DSP based coherent receiver for phase-modulated radio-over-fiber optical links
}

Zibar, Darko; Tafur Monroy, Idelfonso; Peucheret, Christophe; Johansson, L.A.; Bowers, J.E.; Jeppesen, Palle

Published in:

OFC/NFOEC 2008 - 2008 Conference on Optical Fiber Communication/National Fiber Optic Engineers Conference

Link to article, DOI:

10.1109/OFC.2008.4528467

Publication date:

2008

Document Version

Publisher's PDF, also known as Version of record

Link back to DTU Orbit

Citation (APA):

Zibar, D., Tafur Monroy, I., Peucheret, C., Johansson, L. A., Bowers, J. E., \& Jeppesen, P. (2008). DSP based coherent receiver for phase-modulated radio-over-fiber optical links. In OFC/NFOEC 2008 - 2008 Conference on Optical Fiber Communication/National Fiber Optic Engineers Conference (pp. 1-3). IEEE Press. https://doi.org/10.1109/OFC.2008.4528467

\section{General rights}

Copyright and moral rights for the publications made accessible in the public portal are retained by the authors and/or other copyright owners and it is a condition of accessing publications that users recognise and abide by the legal requirements associated with these rights.

- Users may download and print one copy of any publication from the public portal for the purpose of private study or research.

- You may not further distribute the material or use it for any profit-making activity or commercial gain

- You may freely distribute the URL identifying the publication in the public portal 


\title{
DSP based Coherent Receiver for Phase-Modulated Radio- over-Fiber Optical Links
}

\author{
Darko Zibar ${ }^{1}$, Idelfonso Tafur Monroy ${ }^{1}$, Christophe Peucheret ${ }^{1}$, Leif A. Johansson ${ }^{2}$, John E. Bowers ${ }^{2}$ and \\ Palle Jeppesen ${ }^{1}$ \\ 1. Department of Communications Optics \& Materials, COM॰DTU, Ørsteds Plads, byg 343, DK 2800 Kgs. Lyngby, Denmark, 2. Department of \\ Electrical and Computer Engineering, University of California, Santa Barbara, CA 93106, USA \\ dz@com.dtu.dk
}

\begin{abstract}
A novel DSP based coherent receiver for phase modulated radio-over-fiber optical links is reported. Using the proposed digital receiver, signal demodulation of $1.25 \mathrm{~Gb} / \mathrm{s} \mathrm{ASK}$ modulated $10 \mathrm{GHz}$ RF carrier is experimentally demonstrated.

(C)2008 Optical Society of America
\end{abstract}

OCIS codes: (060.1660) Coherent communications; (120.5060) Phase modulation

\section{Introduction}

Radio-over-Fibre (RoF) optical links employing optical phase modulation at the antenna base station have recently attracted large attention [1-3]. An immediate advantage of optical phase modulation over intensity modulation is that the process of imposing a high radio frequency (RF) wireless signal on the optical carrier is inherently linear when conventional phase modulators are used. The phase modulation has thus no fundamental limit on the dynamic range. Additionally, phase modulated RoF optical links yield $6 \mathrm{~dB}$ higher RF signal gain for the same laser power and same fibre link [4]. The challenge to implement a phase-modulated optical link lies in the receiver structure since optical phase modulated links require a coherent receiver. With recent advances in integrated electronic circuits and digital signal processing, coherent receivers using DSP are becoming very attractive [5]. Recent efforts on digital coherent receivers for RoF optical links have mostly focused on analog communication with focus on linear demodulation [3]. Furthermore, in [3] no digital compensation technique was implemented for synchronizing the transmitter and the local oscillator (LO) laser. In this paper, a novel DSP based coherent receiver for digital phase modulated RoF optical links is proposed, numerically investigated and experimentally demonstrated. The proposed receiver uses carrier-recovery digital PLL to compensate for the frequency and phase difference between the transmitter and LO laser, and feedforward carrier recovery to recover the RF signal carrier and thereby demodulate the signal. Additionally, we numerically investigate the bit-error-rate (BER) performance of the receiver in terms of laser linewidth and frequency difference between the LO and transmitter laser.

\section{DSP based coherent receiver for RoF}

The schematic diagram of the proposed phase modulated link and the digital coherent receiver is shown in Fig. 1.

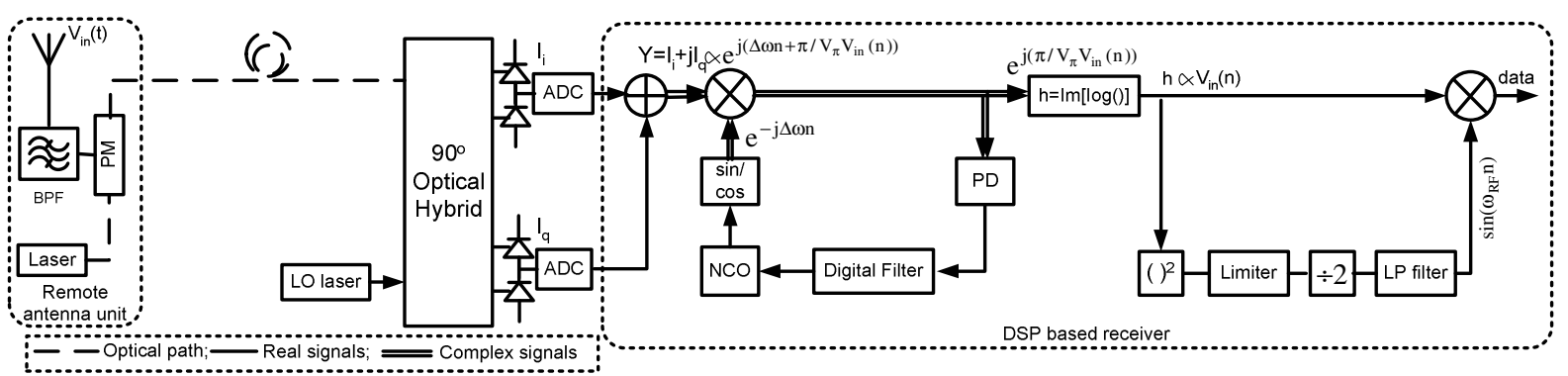

Fig. 1 General outline of a DSP based coherent receiver for RoF links. PM: optical phase modulator, BPF: band-pass filter. NCO: number controlled oscillator, PD: phase detector , f: frequency difference between transmitter and LO laser and $=2 \pi \mathrm{f}$.

The received RF signal, $\mathrm{V}_{\text {in }}(\mathrm{t})$, is first band-pass filtered, and then used to modulate an optical phase modulator at the remote antenna unit. The phase modulated optical data signal is thereafter transported to the receiver unit for data recovery. At the receiver, a 90 optical hybrid is used to mix the received data signal with the LO laser. The inphase $\left(\mathrm{I}_{\mathrm{i}}\right)$ and qudrature $\left(\mathrm{I}_{\mathrm{q}}\right)$ optical signal components are detected with two pairs of balanced photodiodes (BW $10 \mathrm{GHz}$ ) and digitalized separately by analog-to-digital converters (ADC). The digitalized photocurrents form a complex quantity $\mathrm{Y}=\mathrm{I}_{\mathrm{i}}+\mathrm{j} \mathrm{I}_{\mathrm{q}}$ which contains all the necessary information to compensate for the frequency and phase difference between the transmitter and LO laser, recover the RF carrier frequency and recover the data. We use a 
carrier-recovery digital PLL to recover the frequency and phase difference between the LO and transmitter laser [6]. The carrier-recovery digital PLL consists of a phase rotator, phase-detector (PD), digital filter, Number Controlled Oscillator (NCO) and sine/cosine processor. The sine/cosine processor accepts the real NCO phase samples as input and delivers sine and cosine samples of those phases to produce a complex locally generated signal, (see Figure 1). The phase rotator performs a complex multiplication between the data signal (Y) and the locally generated signal to produce a complex frequency difference signal. A phase detector algorithm $(\operatorname{Im}[])$ provides an indication of the phase error. The digital signal from the phase detector is then passed through a digital (first order) filter and the output from the digital filter controls the NCO. When the digital PLL is locked, the frequency and phase difference between the transmitter and LO laser is removed from the complex signal Y. Next, we linearly demodulate the phase encoded RF signal, $V_{\text {in }}$, through the relation $\operatorname{Im}[\ln ()]$ [3]. The signal after linear demodulation is sent to feedforward carrier recovery to recover the RF carrier, whereafter the data can be recovered. The DSP receiver in Figure 1 works for BPSK modulated RF carriers; however, with slight modifications in feedforward-carrier recovery, the receiver can also be used for ASK modulated RF carriers as demonstrated experimentally in section 4.

\section{BER as a function laser linewidth and frequency offset}

In this section, we numerically investigate the BER performance of the DSP based receiver shown in Figure 1, as a function of incoming optical data signal power and frequency difference between the transmitter and LO laser. The RF carrier frequency is at $10 \mathrm{GHz}$ and it is BPSK modulated at $1.25 \mathrm{~Gb} / \mathrm{s}$. The sampling rate is set to $40 \mathrm{Gs} / \mathrm{s}$. In Figure 2(a), the BER of the demodulated $1.25 \mathrm{~Gb} / \mathrm{s}$ signal is computed as a function of incoming optical data signal power as the laser linewidth is varied from 0 to $3 \mathrm{MHz}$. f between the transmitter and LO laser is $150 \mathrm{MHz}$.

(a)

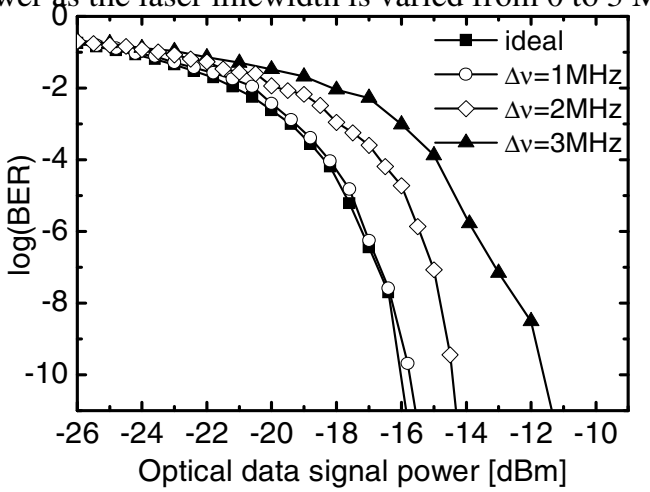

(b)

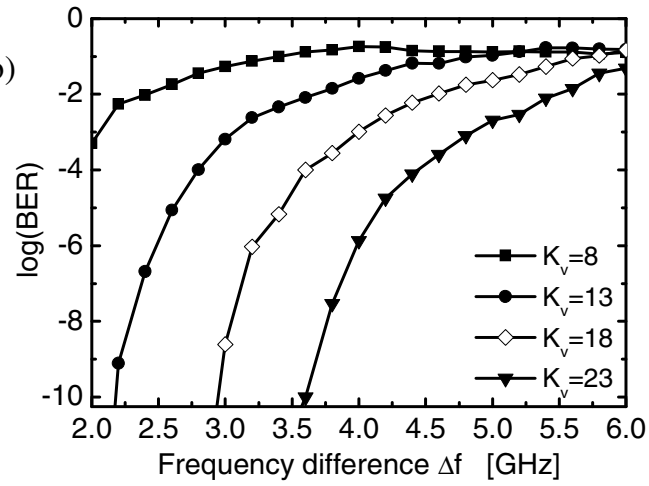

Fig. 2. (a) BER as a function of incoming optical data signal power level for selected values of laser linewidth . f $=150 \mathrm{MHz}$. (b) BER as a function of frequency difference, , between transmitter and LO laser for selected values of NCO scaling coefficient.

Figure 2(a), demonstrates that error free $\left(B E R=10^{-9}\right)$ performance can be obtained using the receiver structure depicted in Figure 1. This means that the carrier-recovery digital PLL can successfully remove $150 \mathrm{MHz}$ frequency difference and also synchronize the phase of the transmitter and LO laser for the considered power levels of the input data signal. It is observed in Figure 2(a), that the performance of the receiver degrades in terms of receiver sensitivity as the laser linewidth is increased from 0 to $3 \mathrm{MHz}$. It is observed that there is almost no penalty in the $\mathrm{BER}$ as the laser linewidth is increased up to $1 \mathrm{MHz}$. However, as the laser linewidth is increased to $2 \mathrm{MHz}$ and 3 $\mathrm{MHz}$, the corresponding penalty is approximately $1.5 \mathrm{~dB}$ and $4 \mathrm{~dB}$, correspondingly. In Figure 2(b), the BER is computed as a function of the frequency difference between the transmitter and LO laser, f, for selected values of the NCO scaling coefficient $\mathrm{K}_{\mathrm{v}}$ (similar to the gain of VCO). $\mathrm{f}$ is varied from $2 \mathrm{GHz}$ to $6 \mathrm{GHz}$. In general, the BER increases as $\mathrm{f}$ is increased. It is observed that when $\mathrm{K}_{\mathrm{v}}=8$, error free performance cannot be obtained in the considered $\mathrm{f}$ range. However, as $\mathrm{K}_{\mathrm{v}}$ is increased, a larger amount of frequency difference can be tolerated. Increasing the NCO scaling coefficient corresponds to increasing the overall bandwidth of the carrier-recovery digital PLL, so that larger $\mathrm{f}$ can be tolerated. It is observed that when $\mathrm{K}_{\mathrm{v}}$ is 23 a frequency difference up to 3.5 $\mathrm{GHz}$ can be tolerated while retaining the BER below $10^{-9}$. When increasing $\mathrm{K}_{\mathrm{v}}$ it should be ensured that all the poles of the carrier-recovery digital PLL are inside the unit circle such that it is operated in stable regime.

\section{Experimental set-up and results}

The experimental set-up for the demonstration of phase modulated RoF optical link is shown in Figure 3. An external cavity tunable CW laser is used at the transmitter ( $100 \mathrm{kHz}$ linewidth). The wavelength of the transmitter 


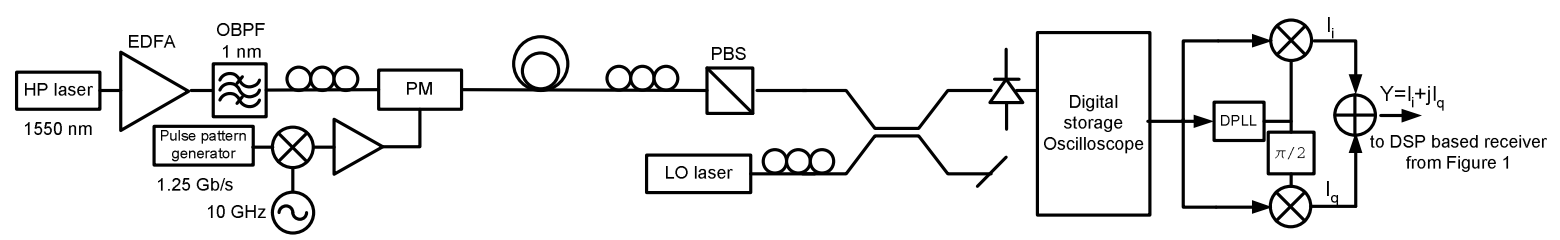

Fig. 3 Experimental set-up for the demonstration of coherent phase modulated RoF link. PBS: polarization beam splitter.

laser is at $1550 \mathrm{~nm}$ and the output of the transmitter CW laser is amplified by a high-power EDFA The data signal consists of a $1.25 \mathrm{~Gb} / \mathrm{s}$ ASK modulated $10 \mathrm{GHz}$ RF carrier and the data signal is then used to drive a conventional lithium-niobate optical phase modulator. The phase modulated optical data signal is then send through $4 \mathrm{~m}$ of fibre and then split in two polarizations using a polarization beam splitter (PBS). Only one polarization is sent to the receiver. At the receiver, a $3 \mathrm{~dB}$ coupler is used to mix the received data signal with the LO laser $(10 \mathrm{MHz}$ linewidth). The wavelength of the LO laser is also set to $1550 \mathrm{~nm}$ and $\mathrm{P}_{\mathrm{LO}}$ is $3 \mathrm{dBm}$. The detected photocurrent is digitalized at a sample rate of $40 \mathrm{Gs} / \mathrm{s}$ using a high-bandwidth real-time sampling scope (Agilent Infiniium DSO80000B with $13 \mathrm{GHz}$ analog bandwidth). The sampled photocurrent is later used for offline signal demodulation and data recovery. Since at the time of the experiment 90 optical hybrid was not available, digital PLL and some extra signal processing were employed in order to recover the in-phase and quadrature optical signal components as shown in Figure 3.
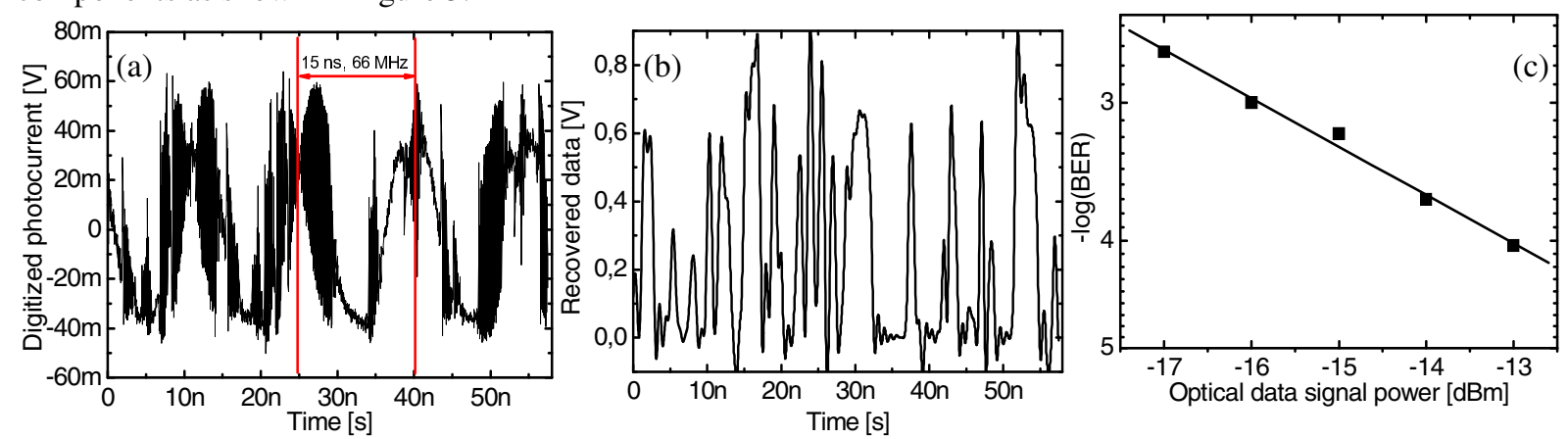

Fig. 4 (a) Time trace of digitized photocurrent. (b) Recovered $1.25 \mathrm{~Gb} / \mathrm{s}$ data using the DSP based receiver from Figure 1. (b) BER as a function of optical data signal power.

Figure 4 illustrates an experimental realization and the subsequent recovered data signal using the DSP based receiver in Figure 1. Figure 4(a) shows the digitized photocurrent by the oscilloscope. It is observed that the digitized photocurrent contains the frequency component associated with frequency difference between the transmitter and LO laser (approximately $66 \mathrm{MHz}$ ), and also the $10 \mathrm{GHz}$ RF carrier. Applying the digitized photocurrent to the DSP based receiver, we are able to remove the frequency difference f, filter laser phase noise, remove the $10 \mathrm{GHz}$ RF carrier, and thereby recover the data signal. The recovered data signal at $1.25 \mathrm{~Gb} / \mathrm{s}$ is shown in Figure 4(b). A smooth trace with clearly distinguished ones and zeros is observed. We have hereby demonstrated that the proposed DSP based receiver can be successfully used for the demodulation and data recovery of the experimental data. In Figure 4(c), a BER curve has been computed as a function of optical data signal power. BER below $10^{-4}$ is achieved at which forward error correction can be used to maintain the transmission quality. Using the proposed digital receiver, linewidth/bit-rate ratio of $810^{-3}$ can thereby be tolerated.

\section{Conclusion}

A novel concept for DSP based receiver for phase modulated RoF optical links has been proposed and demonstrated. By proof-of-principle, it has experimentally been shown that the proposed digital receiver can be used to successfully recover $1.25 \mathrm{~Gb} / \mathrm{s}$ data signal from phase modulated RoF optical link with $10 \mathrm{GHz}$ RF carrier.

\section{References}

[1] H. F. Chou et al., IEEE Photonics Technology Letters, vol. 19, no. 12, pp. 940-942, June 2007

[2] D. Zibar et al., IEEE Photonic Technology Letters, vol. 19, no. 9, pp. 686-688, May 2007

[3] T. R. Clark et al., IEEE Photonic Technology Letters, vol. 19, no. 16, pp. 1206-1208, August 2007

[4] F. Bucholt et al., in Proceeding of Conference on Coherent Optical Technologies (COTA) 2006, Whistler, Canada, paper CFA6, 2006

[5] X. Liu, in Proceedings European Conference on Optical Communication (ECOC) 2007, Berlin, Germany, pp. 143-146, 2007

[6] F. Gardner, "Phase-lock techniques," $3^{\text {rd }}$ edition, John Wiley and sons, 2004 